\title{
Comments on "The Effects of Aerobic and Resistance Exercise Training on Liver Enzymes and Hepatic Fat in Iranian Men With Nonalcoholic Fatty Liver Disease"
}

\author{
Makan Cheraghpour, ${ }^{1}$ Azita Hekmatdoost, ${ }^{2}$ and Alireza Ghaemi ${ }^{3,}{ }^{*}$ \\ ${ }^{1}$ Nutrition and Metabolic Diseases Research Center, Ahvaz Jundishapur University of Medical Sciences, Ahvaz, IR Iran \\ ${ }^{2}$ Department of Clinical Nutrition, Faculty of Nutrition and Food Technology, Shahid Beheshti University of Medical Sciences, Tehran, IR Iran \\ ${ }^{3}$ Department of Basic Sciences and Nutrition, Health Sciences Research Center, School of Public Health, Mazandaran University of Medical Sciences, Sari, IR Iran \\ "Corresponding author: Alireza Ghaemi, Department of Basic Sciences and Nutrition, Health Sciences Research Center, School of Public Health, Mazandaran University of \\ Medical Sciences, Sari, IR Iran. Tel: +98-1133543750, Fax: +98-1133542473, E-mail: ghaemi1387@yahoo.com
}

Received 2015 December 12; Accepted 2016 April 16.

Keywords: Nonalcoholic Fatty Liver Disease, Diet, Exercise Training, Resistance, Aerobic

\section{Dear Editor,}

We read with great interest the article entitled "The Effects of Aerobic and Resistance Exercise Training on Liver Enzymes and Hepatic Fat in Iranian Men With Nonalcoholic Fatty Liver Disease" (1) the authors reported that both the aerobic (AT) and resistance (RT) exercise training significantly reduced the hepatic fat content, alanine amino transferase (ALT), and aspartate amino transferase (AST) levels in patients with nonalcoholic fatty liver disease (NAFLD). However, these results have been shown in previous studies (2-9), and we believe that the current study provides an important contribution to the literature. Therefore, we needed to point out some issues.

NAFLD is a disease that is directly related to lifestyle, so its prevalence is a consequence of the rising incidence of obesity, diabetes, and other metabolic syndrome components (10). On the other hand, it seems that lifestyle modifications and changes in the composition of the diet also play a key role in the treatment of NAFLD (10). Eating fat, saturated/trans, unsaturated fat with an emphasis on omega-3, simple sugars, fiber, processed meats and fast food play a pivotal role in prevention, improvement or worsening of this multifactorial disease. Therefore, it is important to assess the diet of patients because of its potential role in NAFLD. Changes in diet would be considered confounding factors in this study; however, the dietary intakes of the participants in this study have not been evaluated. At the same time, patients with NAFLD should receive dietary advice regarding the most acceptable therapy for their disease (10).

Moreover, it is not clear in this study whether the subjects represented new cases of NAFLD, if they had previously received any therapy, or how long they had been di- agnosed with the disease.

Furthermore, according to the aim of this study, the amount of physical activity at baseline was not determined, and it is not clear if there were any differences between the three groups of patients in terms of their initial total physical activity.

Finally, we suggest that this study be revised once more so that readers of this journal can clearly understand how the effects of daily exercise improve NAFLD.

\section{Footnote}

Authors' Contribution: Makan Cheraghpour and Alireza Ghaemi searched the literature and wrote the article. Alireza Ghaemi had the initial idea, and Azita Hekmatdoost made the English corrections and conducted the review.

\section{References}

1. Shamsoddini A, Sobhani V, Ghamar Chehreh ME, Alavian SM, Zaree A. Effect of Aerobic and Resistance Exercise Training on Liver Enzymes and Hepatic Fat in Iranian Men With Nonalcoholic Fatty Liver Disease. Hepat Mon. 2015;15(10):ee31434. doi: 10.5812/hepatmon.31434. [PubMed: 26587039].

2. Cuthbertson DJ, Shojaee-Moradie F, Sprung VS, Jones H, Pugh CJ, Richardson P, et al. Dissociation between exercise-induced reduction in liver fat and changes in hepatic and peripheral glucose homoeostasis in obese patients with non-alcoholic fatty liver disease. Clin Sci (Lond). 2016;130(2):93-104. doi: 10.1042/CS20150447. [PubMed: 26424731].

3. Guo R, Liong EC, So KF, Fung ML, Tipoe GL. Beneficial mechanisms of aerobic exercise on hepatic lipid metabolism in non-alcoholic fatty liver disease. Hepatobiliary Pancreat Dis Int. 2015;14(2):139-44. [PubMed: 25865685].

4. Keating SE, George J, Johnson NA. The benefits of exercise for patients with non-alcoholic fatty liver disease. Expert Rev Gastroenterol Hepatol. 2015;9(10):1247-50. doi: 10.1586/17474124.2015.1075392. [PubMed: 26289101]. 
5. Loomba R, Cortez-Pinto H. Exercise and improvement of NAFLD: Practical recommendations. J Hepatol. 2015;63(1):10-2. doi: 10.1016/j.jhep.2015.03.009. [PubMed: 25863525].

6. Martins C, Aires L, Junior IF, Silva G, Silva A, Lemos L, et al. Physical Activity is Related to Fatty Liver Marker in Obese Youth, Independently of Central Obesity or Cardiorespiratory Fitness.J Sports Sci Med. 2015;14(1):103-9. [PubMed: 25729297].

7. Ordonez R, Carbajo-Pescador S, Mauriz JL, Gonzalez-Gallego J. Understanding nutritional interventions and physical exercise in nonalcoholic fatty liver disease. Curr Mol Med. 2015;15(1):3-26. [PubMed: 25601465].
8. Takahashi A, Abe K, Usami K, Imaizumi H, Hayashi M, Okai K, et al. Simple Resistance Exercise helps Patients with Non-alcoholic Fatty Liver Disease. Int J Sports Med. 2015;36(10):848-52. doi: 10.1055/s-00351549853. [PubMed: 26090879].

9. Whitsett M, VanWagner LB. Physical activity as a treatment of nonalcoholic fatty liver disease: A systematic review. World J Hepatol. 2015;7(16):2041-52. doi: 10.4254/wjh.v7.i16.2041. [PubMed: 26261693].

10. Ghaemi A, Taleban FA, Hekmatdoost A, Rafiei A, Hosseini V, Amiri Z, et al. How Much Weight Loss is Effective on Nonalcoholic Fatty Liver Disease?. Hepat Mon. 2013;13(12):ee15227. doi:10.5812/hepatmon.15227. [PubMed: 24358045]. 